\title{
COMPUTER-AIDED ASSESSMENT OF EYE-HAND COORDINATION \\ IN CHILDREN WITH MILD MENTAL RETARDATION: A POSSIBle APPLiCATION AS A SCREENING TEST
}

\author{
P. KOWALSKA ${ }^{1}$, M. KRZYWIŃSKA-WIEWIÓROWSKA², \\ M. KAMIENIARZ ${ }^{3}$, A. KRZYŻANIAK ${ }^{2}$, G. KAMIENIARZ ${ }^{1}$ \\ Computational Physics Division, Departament of Physics, \\ Adam Mickiewicz University, Poznań, Poland \\ ${ }^{2}$ Departament of Epidemiology, Chair of Social Medicine \\ Karol Marcinkowski University of Medical Sciences, Poznań, Poland \\ ${ }^{3}$ Clinic of Rehabilitation, Karol Marcinkowski University of Medical Sciences, Poznań, Poland
}

\begin{abstract}
Making use of the earlier designed computer tests assessing the hand dexterity, a study was performed in which the time of task completion was measured in a group of 88 mentally impaired children aged 7-15 and a group 86 of control children. All the children were also asked to take two types of psychological tests: Wechsler test subscales blocks and puzzles and Bender-Santucci test. Results of the computer tests discriminate these groups of children, indicating statistically significant differences between the corresponding mean values. The values of the Pearson coefficient $\left(0.35 \leq r_{P} \leq 0.57\right)$ for the control group point to a relatively high correlation between the computer test results and those of psychological tests. The sensitivity and specificity analysis is also presented to show that the computer tests fulfil the criteria for a screening test.
\end{abstract}

\section{INTRODUCTION}

Mental retardation refers to the group of psychic disturbances, manifested as lower than average intellectual skill and capability of social adaptation. The basic criterion of diagnosing mental impairment is the flowing intelligence index (IQ) defined as the ratio of the age intelligence to the calendar age multiplied by 100 . The flowing intelligence, being biologically determined, is independent of cultural factors. Measurement of flowing intelligence provides the information on potential abilities and allows an assessment of the chances of development of the individual at the optimum motivation and optimum environmental stimulation.

Mental impairment is manifested in different way in different children so its proper recognition should be performed taking into account the four factors of the conception of development:

- genetic factors determining the development of the central nervous system,

- child activity,

- the effect of environment,

- the effect of upbringing.

Diagnostics of mental retardation is difficult and demands careful distinction from environmental neglect, dementia or psychosis. Mental impairment is characterised not only by lower than 
average level of cognitive, intellectual and performance processes but also emotional processes. Correct diagnosis should take into account individual, clinical and social indices. It is estimated that mental impairment appears in 1-2\% of the population. Mild mental retardation is met in $90 \%$ cases. According to the Wechsler's scale, mild mental retardation is described by IQ index from 50 to 69 .

Recently, computer tests checking manual performance have been developed [1,2] in which the subjects are asked to execute 6 functional tests using the mouse. The pace and precision of task performance is recorded on a hard disk. The study on a sufficiently wide sample has been performed, which enabled a determination of age standards for school-age children, the tests have been also verified as to their test-retest reliability [3],

\section{THE AIM OF THE STUDY}

The main aim of the study was the development of a method of computer-aided assessment of eye-hand coordination in children with mild mental retardation and checking the possibility of its prospective diagnostic applications.

The hitherto used psychological methods allowing assessment of eye-hand coordination are time-consuming and demand the engagement of professional psychologists. The method proposed here is easy, friendly for children and possible to be administered by school medical staff. The results can be viewed on a computer monitor screen during the test performance.

\section{MATERIAL AND THE METHOD}

The subjects of the study were 174 children including a control group of 88 (43 boys and 45 girls) of normal mental development. The group of children diagnosed with mild mental retardation (MMR) included special school pupils. The group comprised 86 children (43 boys and 43 girls) aged 7-15. The subjects were selected from among volunteers and the study was performed under expressed parents' consent.

Table I presents the age structure of the control group, where $\mathrm{M}$ stands for boys and $\mathrm{F}$ for girls. The mean age $(m v)$ and standard deviation $(S D)$ are also given. The children diagnosed with mental impairment were characterised with poorer than average mental abilities, impaired physical and social development. The latter characteristics are in general a consequence of their worse developmental conditions in the biological and social sense as a population.

Table I. The age and sex structure of the groups of subjects

\begin{tabular}{lrrrrrrrrr}
\hline \multirow{2}{*}{ Group } & \multicolumn{3}{c}{$7-8$} & \multicolumn{2}{c}{$9-11$} & \multicolumn{2}{c}{$12-15$} & \multirow{2}{*}{ sv } \\
\cline { 2 - 7 } & $\mathrm{M}$ & $\mathrm{F}$ & $\mathrm{M}$ & $\mathrm{F}$ & $\mathrm{M}$ & $\mathrm{F}$ & & \\
\hline Control group & 17 & 14 & 14 & 17 & 12 & 14 & 9.8 & 2.2 \\
Impaired children (MMR) & 1 & 0 & 12 & 14 & 30 & 29 & 12.6 & 2.0 \\
\hline
\end{tabular}


In our MMR group, three types of impairment can be distinguished: biological, social and educational [4-6], As a result of relationships in the psychic structure and between psyche, organism and environment - the occurrence of some deficiencies, defects or functional dysfunctions implied certain negative consequences. The children were qualified to special schools on the basis of a thorough psychological examination at the Psychological-Pedagogical Unit. The intelligence quotient (IQ) determined by the Wechsler test was in the range 69-58. The data on the health status of the children were collected from the school medical documentation and from the relevant paediatrician. The information on the family environment was obtained through a questionnaire study.

Only $5 \%$ of the children were diagnosed with anomalies in central nervous system, which could be related to mental retardation. Only in a few percent of cases the aetiology of this type of impairment can be established because usually it cannot be traced to a single etiological factor. A significant role in the aetiology of this type of impairment play the family factors, including genetic ones, and the environmental factors. It has been estimated that about $80 \%$ of cases of mild mental retardation appeared on the family-cultural background. Over $90 \%$ of cases of mild mental retardation occur in children from lower social strata and the correlation between the intelligence of the parents and the children is $\sim 0.5$, while in the cases of more severe mental retardation this correlation is close to 0 . The level of the parents' education determines the possibilities of employment and the standard of living. In the population studied over $90 \%$ of parents had incomplete elementary education, elementary education or vocational training. The level of unemployment reached for fathers $20 \%$, whereas for mothers almost $50 \% ; 5 \%$ of fathers and $7 \%$ of mothers received health or social benefits.

The children with mental impairment were also characterised by poorer physical development, and were usually smaller than their healthy peers. Other often met disorders were faulty posture $(69 \%)$ and vision defects $(25 \%)$.

Prior to taking up computer tests the children were carefully instructed on the way of execution of particular tasks and were allowed to some trial tests in order to comprehend the action of the computer mouse. After the preliminary preparation the children were asked to perform the tests and each test was repeated three times. The following statistical analysis was made of the mean values from the three measurements. The tests were performed at random sequence in order to avoid the effect of selectivity of the samples. The children from the control group were asked to perform three tests with each hand and after one week the other three tests. The children with mental impairment were asked to perform all the tests with only the dominant hand on one occasion.

The children were also examined by a paediatrician [7] following the protocol of balance examination of children aged 6,10,14 and 18, and of clinical examination - including the description of possible chronic diseases and assessment of physical development.

In order to verify the indications of the computer test, the members of both groups were subjected to traditional psychological tests (Wechsler), and Bender in the version proposed by 
Santucci [8-10], The Wechsler test is commonly used for assessment of the intelligence quotient in order to e.g. estimate the school maturity. The test is composed of two parts with and without the use of words. For the sake of comparison with the computer test results, two subscales allowing the assessment of eye-hand skills (blocks and puzzles) were used. The tests were not used for clinical assessment so it was not necessary to perform the whole test [8-11]. The BenderSantucci test involves copying certain figures and has been often used for assessment of eye-hand functions.

\section{RESULTS}

Statistical analysis was carried out using the program InStat made by GraphPad and Statistica by StatSoft. Earlier study has shown [1] that to ensure the normality of the distribution and uniformity of variation, the computer data should be transformed. That is why statistical analysis was performed here for natural logarithm of the real mean values of three measurements performed in the experiment.

The first stage of statistical analysis was to verify the correlation between the computer test results and psychological tests results in the control group (Table II) and in the group of mentally impaired children (Table III). The first column of the tables presents the names of the tasks performed on a computer. The next column gives the Pearson coefficients $\left(r_{P}\right)$ calculated for the correlation between the results of the computer tests and the Wechsler test - blocks. The third column presents the $p$-values obtained in the test that verify if the Pearson coefficient is statistically significantly different from zero. The fourth column gives the Spearman correlation coefficients $\left(r_{s}\right)$. The next three columns present the results of the correlation with the subscale puzzles and the last three - with the Bender-Santucci test results.

Table II. The Pearson $\left(r_{P}\right)$ and Spearman $\left(r_{S}\right)$ correlation coefficient values of the correlation between the psychological tests and computer tests in the control group and $p$-value of the test for statistical significance of the Pearson coefficient being different from zero

\begin{tabular}{lcccccccccc}
\hline \multirow{2}{*}{ Tests } & \multicolumn{3}{c}{ Wechsler-blocks } & \multicolumn{3}{c}{ Wechsler-puzzles } & \multicolumn{3}{c}{ Bender-Santucci } \\
\cline { 2 - 10 } & $r_{p}$ & $p$-value & \multicolumn{1}{c}{$r_{s}$} & \multicolumn{1}{c}{$r_{p}$} & $p$-value & \multicolumn{1}{c}{$r_{s}$} & $r_{p}$ & $p$-value & $r_{s}$ \\
\hline Blocks & 0.5445 & $<0.0001$ & 0.6088 & 0.4831 & $<0.0001$ & 0.5315 & 0.5625 & $<0.0001$ & 0.5956 \\
Circle & 0.4853 & $<0.0001$ & 0.5495 & 0.3935 & $<0.0001$ & 0.4435 & 0.4526 & $<0.0001$ & 0.5206 \\
Labyrinth & 0.5677 & $<0.0001$ & 0.6254 & 0.5055 & $<0.0001$ & 0.5254 & 0.4988 & $<0.0001$ & 0.5282 \\
Ball & 0.4689 & $<0.0001$ & 0.4945 & 0.3626 & 0.0004 & 0.3844 & 0.5282 & $<0.0001$ & 0.5558 \\
Board & 0.5749 & $<0.0001$ & 0.6253 & 0.5208 & $<0.0001$ & 0.5335 & 0.5647 & $<0.0001$ & 0.6017 \\
Centres & 0.3973 & $<0.0001$ & 0.4826 & 0.3504 & 0.0007 & 0.3691 & 0.4414 & $<0.0001$ & 0.4376 \\
\hline
\end{tabular}


Table III. The Pearson $\left(r_{P}\right)$ and Spearman $\left(r_{S}\right)$ correlation coefficients between the results of the psychological tests and computer tests in the group of mentally impaired children, and the $p$-value of the test checking if the Pearson coefficient is statistically significantly different from zero

\begin{tabular}{lcccccccccl}
\hline \multirow{2}{*}{ Tests } & \multicolumn{3}{c}{ Wechsler-blocks } & \multicolumn{3}{c}{ Wechsler-puzzles } & \multicolumn{3}{c}{ Bender-Santucci } \\
\cline { 2 - 11 } & $r_{P}$ & $p$-value & $r_{S}$ & $r_{P}$ & $p$-value & $r_{S}$ & $r_{P}$ & $p$-value & $r_{S}$ \\
\hline Blocks & 0.6018 & $<0.0001$ & 0.3808 & 0.5533 & $<0.0001$ & 0.454 & 0.5083 & $<0.0001$ & 0.4805 \\
Circle & 0.2356 & 0.032 & 0.1902 & 0.2048 & 0.0633 & 0.2033 & 0.1326 & 0.2321 & 0.09585 \\
Labyrinth & 0.3512 & 0.011 & 0.3155 & 0.343 & 0.0015 & 0.3224 & 0.2425 & 0.0272 & 0.2433 \\
Ball & 0.4052 & 0.0001 & 0.4118 & 0.352 & 0.0011 & 0.3523 & 0.3016 & 0.0056 & 0.3741 \\
Board & 0.5119 & $<0.0001$ & 0.4586 & 0.4323 & $<0.0001$ & 0.3664 & 0.4641 & $<0.0001$ & 0.4579 \\
Centres & 0.08235 & 0.4592 & 0.06783 & 0.1283 & 0.2476 & 0.09599 & 0.04020 & 0.7182 & 0.05526 \\
\hline
\end{tabular}

Analysis of the data for the control group has shown a strong correlation between the raw results of the psychological tests and the computer tests $(p$-value $<0.0001)$. Only the correlation between the test Centres and the psychological tests was intermediate $\left(r_{P}=0.40\right.$ for Wechsler blocks, $r_{P}=0.35$ for Wechsler - puzzles and $r_{P}=0.44$ for Bender-Santucci test). The strongest correlation with the results of all the three psychological tests was found for the results of the test Board (the Pearson correlation coefficient varied from 0.52 to 0.57 ). The Spearman coefficient value for all manual manipulations is for the Wechsler test - blocks $0.48<r_{S}<0.63$, for the Wechsler test - puzzles $0.37<r_{s}<0.53$ and for the Bender-Santucci test $0.44<r_{S}<0.60$, which also indicates a statistically significant correlation among the results. As follows from the data in Table III, the correlation between the results of psychological tests for MMR children and the logarithms of the mean times of computer tests performance was weaker. The highest correlation was found for the tests Blocks and Board with $r_{P}$ taking values 0.51-0.60 and 0.430.51 , respectively. The correlation between the logarithms of times of the Circle test performance and the results of Wechsler-puzzle test and Bender-Santucci test was poor and statistically insignificant. The Pearson coefficient was 0.2048 for the level of significance 0.0633 and 0.1326 for the level of significance 0.2321 . No statistically significant correlations ( $p$-value $>0.05$ ) were found for the computer test Centres $\left(0.04<r_{P}<0.13\right)$. Statistical significance of the differences in the computer test results between the MMR children and those from the control group was also checked. The groups studied were divided into three subgroups according to age: 7-8, 9-11 and 12-15. The number of mild mentally impaired children age 7-8 was too small so that for this group the calculations were abandoned. The results are presented in Table IV. 
Table IV. Logarithms of mean times of computer test completion and mean times of computer test completion for the dominant hand, $p$-values of t-Student test checking the statistical significance between the results for children in the age groups 9-11 and 12-15

\begin{tabular}{|c|c|c|c|c|c|c|c|c|c|}
\hline \multirow{3}{*}{ Tests } & \multicolumn{4}{|c|}{ Age: $9-11$} & \multicolumn{4}{|c|}{ Age: $12-15$} & \multirow{3}{*}{$p$-value } \\
\hline & \multicolumn{2}{|c|}{ MMR group } & \multicolumn{2}{|c|}{ Control group } & \multicolumn{2}{|c|}{ MMR group } & \multicolumn{2}{|c|}{ Control group } & \\
\hline & $\ln t$ & $t[\mathrm{~s}]$ & $\ln t$ & $t[\mathrm{~s}]$ & $\ln t$ & $t[\mathrm{~s}]$ & $\ln t$ & $t[\mathrm{~s}]$ & \\
\hline Blocks & 3.075 & 23.654 & 2.199 & 9.658 & 2.573 & 13.907 & 1.808 & 6.402 & $<0.0001$ \\
\hline Circle & 2.597 & 14.023 & 2.108 & 8.828 & 2.475 & 12.82 & 1.861 & 6.793 & $<0.0001$ \\
\hline Labyrinth & 3.222 & 28.747 & 2.557 & 13.849 & 2.94 & 20.796 & 2.228 & 9.713 & $<0.0001$ \\
\hline Ball & 0.8585 & 2.487 & 0.5083 & 1.763 & 0.649 & 2.009 & 0.1843 & 1.263 & $<0.0001 *$ \\
\hline Board & 3.909 & 52.542 & 3.248 & 27.550 & 3.563 & 36.878 & 2.873 & 18.454 & $<0.0001$ \\
\hline Centres & 3.317 & 29.395 & 2.925 & 19.274 & 3.351 & 30.484 & 2.794 & 16.606 & $<0.0001$ \\
\hline
\end{tabular}

* in age group $9-11, p=0.0002$

The first column of Table IV gives the names of the tests. The second and fourth columns present the logarithms of the mean times of computer tests completion for the age group 9-11 for MMR and control group children. The third and fifth columns contain the times of tests completion in seconds. The next four columns give the corresponding data for the age group 12-15. The last column includes the $p$-values of the t-Student test. Prior to statistical analysis the results obtained for the control group were compared with the standards given in Table II of [1]. On average, the children from the control group completed the tests in shorter time, however within the upper limit of the normative data.

Our important result is that the difference in the task completion time obtained for MMR children and for those from the control group is statistically significant for both age groups (Table IV). The $p$-value of the t-Student test was much lower than the level of significance $(p<0.0001)$. In most cases MMR children performed the tests in twice longer times than the children from the control group. This study shows that computer tests can discriminate between children with normal and retarded development and implies the construct validity of our tests.

Table $\mathrm{V}$ presents the results of a detailed correlation analysis between the psychological tests. It was performed on the basis of the data obtained for the MMR children and the control group. The first column specifies the tests between which the correlation is studied. The second column includes the Pearson coefficients $\left(r_{P}\right)$ calculated for the control group, the third one comprises the $p$-value checking the statistical significance of $r_{P}$ being different from zero, and the fourth one gives the Spearman con-elation coefficients $\left(r_{S}\right)$. The last three columns present the corresponding data for MMR children.

From Table $\mathrm{V}$ it follows that a strong and statistically significant positive correlation was obtained between the results of the psychological tests ( $p$-value $<0.0001)$. The Pearson coefficient was $0.74<r_{P}<0.83$ for the control group and $0.71<r_{P}<0.75$ for the MMR children. High values of the Spearman coefficient also prove a strong correlation. 
Table V. The Pearson $\left(r_{P}\right)$ and Spearman $\left(r_{S}\right)$ coefficient values characterising the correlation between the results of Wechsler tests (puzzles, blocks) and Bender-Santucci tests for the children with mild mental retardation and the control group, $p$-values of the t-Student test checking the significance of the Pearson coefficient being different from zero

\begin{tabular}{lcccccc}
\hline \multirow{2}{*}{ Psychological tests } & \multicolumn{3}{c}{ Control group } & \multicolumn{3}{c}{ MMR group } \\
\cline { 2 - 7 } & $r_{P}$ & $p$-value & $r_{S}$ & $r_{P}$ & $p$-value & $r_{s}$ \\
\hline Puzzles - blocks & 0.8257 & $<0.0001$ & 0.7897 & 0.7548 & $<0.0001$ & 0.6676 \\
Puzzles - Bender-Santucci & 0.7507 & $<0.0001$ & 0.7224 & 0.7135 & $<0.0001$ & 0.6416 \\
Blocks - Bender-Santucci & 0.7423 & $<0.0001$ & 0.7603 & 0.7524 & $<0.0001$ & 0.7597 \\
\hline
\end{tabular}

In our study we would like to check if the computer tests could be used to asses the eye-hand coordination, referring to the criterion-related model. The corresponding Pearson coefficients, showing the strength of the correlation with the psychological eye-hand coordination tests, are collected in Table III. It is important that the correlations are statistically significant, but the proper measure of the criterion validity is the determination coefficient $r_{p}^{2}$. The determination coefficient $\left(r_{P}^{2}\right)$ shows how much variability of computer test results is caused by changes in the hand-eye coordination. For our tests the determination coefficients range between 0.16 and 0.32 . There is no sharp commonly accepted value as the lower bound. If we assumed $r_{P}=0.5$ (as is often the case and gives $r_{P}^{2}=0.25$ ), then only 3 of our tests would fulfil the condition for the criterion-related validity. However, lowering the barrier to $r_{P}=0.45$, which corresponds to $r_{P}^{2}=0.20$, all our tests are criterion valid with only one exception for Centres. We can now compare these results with the corresponding inter-correlations for the psychological tests given in Table V. We find only in one case $r_{P}^{2}=0.69$, whereas in the remaining cases $0.50 \leq r_{P}^{2} \leq 0.57$.

Having checked that the computer tests display the criterion validity with respect to the psychological test of the eye-hand coordination at least on the moderate level, we can discuss if they can be applied for screening purposes. We have adopted the following procedure.

Performing the traditional tests utilized in Psycho-Pedagogical Clinics (Wechsler-subtest blocks and puzzles, Bender-Santucci test and some extra examination - if necessary), the school psychologists were also asked to assess if visual-motor (hand-eye) coordination of a given child was normal or abnormal. Then the diagnostic validity of the computer tests was checked by sensitivity and specificity [12-14] examination. The sensitivity means a ratio of a number of subjects with a positive computer test result to all those with abnormal behaviour. Specificity has been defined as a ratio of number of subjects with negative test results to those whose visualmotor coordination in the traditional psychological tests is normal.

Those two characteristics of a test (sensitivity and specificity) depend on criteria for test norm selected. The highly sensitive test is also characterized by low specificity and vice versa. If the norm means the result contained within \pm 1 standard deviation, then sensitivity of respective computer tests is from 24.4 to $54.8 \%$ (see Table VI). 
Table VI. The values of sensitivity and specificity calculated for five different values of norm's width

\begin{tabular}{|c|c|c|c|c|c|c|c|c|c|c|}
\hline \multirow[b]{2}{*}{ Tests } & \multicolumn{2}{|c|}{$\ln t \pm 1 / 3 S D$} & \multicolumn{2}{|c|}{$\ln t \pm 1 / 2 S D$} & \multicolumn{2}{|c|}{$\ln t \pm 3 / 4 S D$} & \multicolumn{2}{|c|}{$\ln t \pm 1 S D$} & \multicolumn{2}{|c|}{$\ln t \pm 2 S D$} \\
\hline & $\begin{array}{c}\text { sensitivity } \\
{[\%]}\end{array}$ & $\begin{array}{c}\text { specificity } \\
{[\%]}\end{array}$ & $\begin{array}{c}\text { sensitivity } \\
{[\%]}\end{array}$ & $\begin{array}{c}\text { specificity } \\
{[\%]}\end{array}$ & $\begin{array}{c}\text { sensitivity } \\
{[\%]}\end{array}$ & $\begin{array}{c}\text { specificity } \\
{[\%]}\end{array}$ & $\begin{array}{c}\text { sensitivity } \\
{[\%]}\end{array}$ & $\begin{array}{c}\text { specificity } \\
{[\%]}\end{array}$ & $\begin{array}{c}\text { sensitivity } \\
{[\%]}\end{array}$ & $\begin{array}{c}\text { specificity } \\
{[\%]}\end{array}$ \\
\hline Blocks & 66 & 73 & 65.8 & 74.1 & 58.5 & 77.8 & 43.9 & 83 & 12.2 & 97.8 \\
\hline Circle & 66 & 53 & 63.4 & 60 & 61 & 65.2 & 54.8 & 72 & 19 & 98.5 \\
\hline Labyrinth & 71 & 53 & 65.8 & 53.3 & 63.4 & 65.2 & 53.7 & 71 & 29.3 & 83.8 \\
\hline Ball & 61 & 61 & 58.5 & 67.4 & 51.2 & 77 & 39 & 82.3 & 12.2 & 96.3 \\
\hline Board & 61 & 73 & 56.1 & 77.9 & 39 & 84.4 & 24.4 & 90.4 & 4.9 & 97.8 \\
\hline Centres & 61 & 54.1 & 58.5 & 61.5 & 53.7 & 68.1 & 46.3 & 77.2 & 21.9 & 92.6 \\
\hline
\end{tabular}


Detailed sensitivity and specificity analysis for the corresponding tests with respect to varied fraction of the standard deviation, is given in Table VI. The first column of Table VI presents the test's names. The second and third contains the values of sensitivity and specificity for the norm calculated using formula In $t \pm 1 / 3$ of the standard deviation $(S D)$. Next columns give the sensitivity's and specificity's values calculated respectively for $1 / 2,3 / 4,1$, and 2 of standard deviation. The values of norms were determined using the standards previously published [1].

The selection of cut-off values for screening tests is difficult. However, taking into account that the test is meant for monitoring as well as that it could used in schools for mentally retarded whereby high specificity is required, we suggest taking $3 / 4$ of standard deviation as norm for further use. Depending on the task, the values of sensitivity vary then from 39 to $63 \%$, whereas the corresponding specificity values reach the level from 65 to $84 \%$.

\section{CONCLUSIONS}

The results of all computer tests in the group of mild mentally retarded children are statistically significantly different from those obtained in the control group.

Apart from one case, the task-completion time of the computer tests is highly correlated with the results of the psychological tests, yielding moderate criterion-related validity for the assessment of the eye - hand coordination.

The proposed computer tests might be applied as simple screening tests for checking the eyehand coordination, selecting as a cut-off the corresponding mean value $\pm 3 / 4 S D$.

\section{Acknowledgements}

We would like to thank Prof. E. Hornowska for discussion about some aspects of the psycho-motor tests and Mrs. K. Jaśniewicz-Pacer for her technical assistance.

\section{References}

[1] M. Kamieniarz et al., Post. Rehabil., 15, 23 (2001).

[2] M. Kamieniarz, W. Stryła, P. Kowalska, G. Kamieniarz, Standardised Computer Tests for Assessment of the Children Hand Dexterity, $1^{\text {st }}$ World Congress of the International Society of Physical and Rehabilitation Medicine (ISPRM I), eds. Peek W. J and Lankhorst G. J., Monduzzi Editore, Bologna 2001.

[3] M. Kamieniarz et al., Comp. Meth. Sci. Tech., 8, 1 (2002).

[4] G. Gollnitz, Psychiatr. Neurol. Med. Psychol. Beib. 13-14, 49 (1970).

[5] G. Neuhauser, Fortschr. Med. 93(25), 1159 (1975).

[6] D. Stomma, Upośpledzenie umysłowe. W: Neurologia dzieciaca, ed. J. Czochańska, Warszawa, PZWL, 203 (1985).

[7] B. Woynarowska, Testy przesiewowe u dzieci i młodziezy $w$ wieku przedszkolnym i szkolnym, Instytut Matki i Dziecka, Warszawa (1990).

[8] E. Hornowska, Testy psychologiczne, teoria i praktyka, Wydawnictwo Naukowe Scholar, Warszawa (2001). 
[9] J. Brzeziński, E. Hornowska (ed.), Skala inteligencji Wechslera WAIS-R, Wydawnictwo Naukowe PWN, Warszawa (1993).

[10] A. Anastasi, S. Urbina, Testy psychologiczne, Pracownia Testów Psychologicznych Polskiego Towarzystwa Psychologicznego, Warszawa (1999).

[11] K. Sommerfelt et al., Pediatr. Neurol. 26(3) (2002).

[12] C. H. Hennekens, J. E. Buring, Epidemiology in Medicine, Little, Brown and Company, BostonToronto (1987).

[13] Z. J. Brzeziński, K. Szamotulska, Epidemiologia kliniczna, Warszawa, PZWL (1997).

[14] W. Jędrychowski, Epidemiologia wprowadzenie i metody badań, Warszawa, PWZL (1999). 